and photon interaction is now possible and desirable.

Hence we see that when atoms group together to form a complex the atomic properties of the constituent atoms are altered. The modification of the properties of isolated atoms is not only evident in clusters, liquids and solids but also in the different types of chemically bonded polyatomic molecules. The Auger electron yield is a property characteristic of a particular atom but it has been reported (Mathews \& Hopkins Phys. Rev. Lett. 40, 1326; 1978) to be dependent on the symmetry and size of the molecule containing the atom. Matthews and Hopkins have investigated the Auger electron LMM yield for sulphur atoms in $\mathrm{H}_{2} \mathrm{~S}, \mathrm{SO}_{2}$ and $\mathrm{SF}_{6}$ and the KLL electron emission from carbon in $\mathrm{CH}_{4}, \mathrm{CCl}_{4}$ and $\mathrm{CF}_{4}$. They have reported that the carbon KLL Auger cross section is largest for $\mathrm{CH}_{4}$, falling by $11 \%$ for $\mathrm{CF}_{4}$ and $25 \%$ for $\mathrm{CCl}_{4}$. Although all of these molecules are tetrahedral the lowest yields are obtained from the molecules which have the largest electron density in the

\title{
Botanical fingerprints
}

\section{from Peter D. Moore}

Deposits of silica in the epidermal cells of grasses produce distinctive 'silica bodies' or phytoliths, which can take on a considerable variety of forms. The shape of phytoliths is reasonably constant within a species, but size varies. Distinctions between species on the basis of shape has not proved very successful and often it has not been possible to proceed beyond the tribe level in phytolith identification.

The desire to identify phytoliths has arisen largely because of palaeoecological studies on both soils and peat deposits. Since these resistant, siliceous structures survive when the bulk of the grass litter decays, they remain as microfossils in a variety of situations. For example, Finney and Farnham (Proc. 3rd Int. Peat Congr., Quebec, $102 ; 1968)$ recovered phytoliths from the inorganic fraction of peat deposits from northern Minnesota. This involved a slow oxidation of peats for up to three weeks using $\mathrm{H}_{2} \mathrm{O}_{2}$. They found high concentrations of phytoliths in the superficial layers of peat (over $5 \%$ of oven dry weight) at the two sites which they examined, and this can probably be associated with human management

Peter D. Moore is a Senior Lecturer in the Department of Plant Sciences, King's College, London. region surrounding the central carbon atoms. In the case of the sulphur LMM electron yield the variation is much more apparent. The cross sections for the characteristic LMM yield in the linear $\mathrm{H}_{2} \mathrm{~S}$ and $\mathrm{SO}_{3}$ molecules are the same but this yield is reduced by $50 \%$ in the octahedral $\mathrm{SF}_{6}$ molecule. In addition an anomalous Auger electron yield is detected at $50 \mathrm{eV}$ below the characteristic peak position. Nevertheless the sum of the anomalous and reduced characteristic yields equals the total expected yield.

Matthews and Hopkins argue that the changes in the Auger yield are not a result of a variation in the binding energies of the sulphur $2 \mathrm{p}$ or carbon $1 \mathrm{~s}$ electrons but due to the influence of the valence electrons on the Auger electrons as they travel out from the centre of the molecule. They suggest that the Auger yield is modified by energy loss collisions or possibly other mechanisms associated with the valence electron cloud, for example, potential-barrier scattering or a double Auger process. is not an inevitable conclusion. Evidence of this sort has recently been presented by Pearsall (Science 199, 177; 1978) for soils derived from the archaeological sites of Real Alto, Ecuador. The presence of large phytoliths in these samples led her to examine the possibility of defining maize phytoliths on the basis of size criteria and thus determining whether maize was grown in the area in the third millennium $\mathrm{BC}$.

Pearsall examined the native grass genera having the same, cross-shaped phytoliths as maize and found that their silica bodies all fell below $16 \mu \mathrm{m}$. Various modern races of maize were also examined and they produced phytoliths ranging from 6 to $25 \mu \mathrm{m}$, but overall $32 \%$ of their phytoliths exceeded $16 \mu \mathrm{m}$. In the archaeological material, 100 phytoliths were counted in each of 17 samples. Twelve samples contained the cross-shaped type, a total of 42 in all. Of these $15(36 \%)$ exceeded $16 \mu \mathrm{m}$ in size. Pearsall interprets this as indicative of maize cultivation on site. What is needed now are more extensive numerical analyses of modern phytoliths to test the reliability of size criteria and also further work on the movement of phytoliths in soils, plant debris and dust to establish their potential for long-distance transport. These microfossils could be a valuable source of information for palaeoecologists which is currently underexploited.

of grassland and consequent soil erosion by wind in recent times. In other aspects the two sites differed. One, at which peat accumulation commenced soon after deglaciation, showed initial low phytolith abundance which increased gradually about half way up the $5 \mathrm{~m}$ profile. At the other site, phytolith abundance rose in the basal peats and remained high; this site was probably younger, perhaps $6,000-7,000$ years old. Finney and Farnham account for the increasing abundance of phytoliths within the post-glacial in terms of contemporaneous expansion of prairie vegetation in the west and south of Minnesota.

Phytoliths can thus provide a useful index of grassland history and of human land use patterns. Also, their abundance in ombrotrophic peats which receive water and nutrient input from rainfall rather than from drainage water, suggests that phytoliths are carried from place to place as airborne particles.

Phytolith microfossils survive in soils (see, for example, Jones \& Beavers Soil Soc. Amer. Proc. 27, 438; 1963), where they can be interpreted as providing evidence of grass species growing in situ, although given the possibility of aerial transport as dust, this

\section{Erratum}

In the article 'gamma-ray spectroscopy in astrophysics' (News and Views 273, 591; 1978) the second author's name should be T. L. Cline and not $T$. L. Kline.

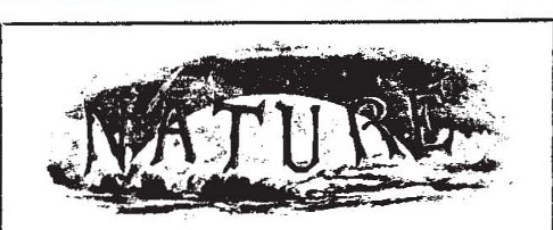

\section{A hundred years ago}

A Subject-Index to Scientific Periodical Literature

I BEG permission to ventilate in your columns a subject which must make itself folt more or less to all your readers, viz., the want of some subjectindex to the vast amount of material scattered about in the numerous scientific periodical publications of the present day. It is true we have the admirable catalogue of the Royal Society, but unless you are acquainted with the name of every author who has written on your subject, it is nearly hopeless attempting a complete bibliography of it.

From Nature 18, 4 July, 251; 1878. 